\title{
Rosalba CAMPRA. En los dobleces de la realidad. Exploraciones narrativas. León: Eolas Ediciones, 2019, 219 pp. ${ }^{1}$
}

La prestigiosa editorial independiente Eolas Ediciones, cuya sede se encuentra en León, España, inauguró hacia fines de 2019 una nueva línea de publicaciones denominada Estudios de lo insólito dedicada a la difusión de contribuciones académicas de índole teórico o bien de aproximaciones críticas y analíticas propicias para el estudio de las diferentes categorías de lo literario no mimético (fantástico, ciencia ficción, realismo mágico, etc.), focalizada en la producción española e hispanoamericana actual. Se trata de una colección de estudios que opera de forma complementaria a la serie de publicaciones de obras de ficción denominada Narrativas de lo insólito, en donde encontramos obras de José María Merino y Cecilia Eudave, entre otros destacados escritores contemporáneos. Es importante señalar que esta nueva línea de publicaciones surge en asociación con el Grupo de Estudios literarios y comparados de lo Insólito y perspectivas de Género (GEIC) de la Facultad de Filosofía y Letras de la Universidad de León; grupo que es dirigido por la destacada investigadora y profesora titular de la cátedra de teoría de la literatura y literatura comparada, dra. Natalia Álvarez Méndez.

Bajo este relevante marco de amistad cultural para con la investigación y la difusión de los estudios literarios, aparece como primera publicación el libro En los dobleces de la realidad. Exploraciones narrativas, de la reconocida intelectual argentina Rosalba Campra, cuya producción se ha situado con relevancia dentro del campo de los estudios literarios hispanoamericanos. Así por ejemplo, en su notable obra teórica, crítica y creativa, aparecen títulos como Territorios de la ficción. Lo fantástico (2008), Itinerarios en la crítica hispanoamericana (2014) y Ficciones desmedidas (2015), entre otros. Además, Rosalba Campra se destaca por su labor de académica y formadora de nuevos especialistas en literatura hispanoamericana desde la dirección de la Cátedra de Literatura Hispanoamericana de la Universidad de Roma, La Sapienza. Por cuanto se trata de una investigadora que sin duda sobresale con total propiedad dentro de una gran generación de mujeres intelectuales argentinas, integrada en otras por Susana Reisz, Pampa Arán, Josefina Ludmer y Beatriz Sarlo. Intelectuales que además representan toda una escuela de reflexión que ha sido capaz de leer a nuestra literatura, problematizándola de una manera sin duda original.

El libro En los dobleces de la realidad. Exploraciones narrativas, se articula desde una continuidad de ideas ya expresadas por Campra en Territorios de la ficción. Lo fantástico. Así, por ejemplo, la figura relativa a "los dobleces de la realidad" es

\footnotetext{
${ }^{1}$ La presente reseña forma parte del proyecto de investigación posdoctoral, titulado "El poema 'fantastizado'. Hacia un giro ficcional/fantástico en la poesía chilena y española contemporánea". Financiamiento de ANID, folio $N^{\circ}$ 74190101, periodo 2019-2021. Tutor patrocinante: Dr. Niall Binns (Universidad Complutense de Madrid, España).
} 
también una forma de expresión creativa para referir otra vez a la literatura fantástica como aquella que se nos revela desde el halo impreciso de la figuración del doble, las sirenas y los fantasmas.

Organizado en cinco capítulos, el libro nos presenta varias reflexiones altamente eruditas, teóricas, críticas y creativas, por lo que cada capítulo bien puede ser revisado de manera correlativa y secuencial conforme con su ordenamiento. En esto, es oportuno mencionar cada uno de los cuatro intermedios narrativos (microrrelatos) que Rosalba Campra ubica entre uno y otro capítulo con el fin de asociar de manera fluida lo ya leído a lo por leer. En efecto, tales intermedios consisten en cuatro microrrelatos ficcionales, muy insólitos, cuyos títulos, paradojalmente, pretenden ser teóricos, propiamente disciplinares: "Literaturas comparadas o los secretos de la correlación", "Retóricas discursivas o la realidad como efecto", "traslapamientos textuales o el diseño y abolición de confines" y "La voz y su sentido o ¿cuánto cuenta quien cuenta?", asociando la disciplinada reflexión académica con la libertad de la creación literaria.

El primer capítulo "Descartar, seleccionar, clasificar. ¿qué hacer con las sirenas?" concentra su atención en las figuraciones de las sirenas, en tanto objeto de interés ya desarrollado en las ficciones narrativas de Campra y, a la vez, como una figura propicia para el debate respecto de las formas de representación de lo fantástico y de su categorización en los estudios literarios. Por ello, el capítulo se inicia con una alusión representativa de la presencia de las sirenas en la narrativa de la autora o de su exploración ficcional, para luego ahondar desde la curiosidad del quehacer crítico en una reflexión de índole fenomenológica y organizativa de lo fantástico. En esto, Campra remite a la obra de Homero, Borges y Cortázar, como también a José Eduardo Agualusa e incluso el diario de Cristóbal Colón y las fotografías de Joan Fontcuberta, pero sobre todo estudia la relación de las tres sirenas homéricas Parténope, Ligia y Leucosia con la obra de Manuel Mujica Lainez, Giuseppe Tomasi de Lampedusa y de la figura autoral de Nathalie-Charles Henneberg; sin olvidar a otros importantes autores como Leopoldo Lugones, Livio Santoro y Franz Kafka. Con ello, la autora reflexiona de la relación entre las sirenas y el orden; o bien, en sus fundamentos de orden y sus insidias de clasificación abarcando las obras de distintos autores y lenguas, como de distintas tradiciones literarias y géneros. Después de todo, durante la lectura del capítulo también recordaremos con Platón que "la armonía del universo depende precisamente de la armonía del canto de las sirenas" (p. 22).

El segundo capítulo, “¿De dónde vienen los fantasmas? ¿y hacia dónde van?” Campra refiere sobre todo las posibilidades de explicación para un origen de los relatos fantásticos, en tanto razón de escritura y afán lector. O bien, de los motivos que permiten una explicación ante la constante invasión de los fantasmas en la literatura según la experiencia que se tenga de la lengua o de la materia verbal en donde ocurre la escritura propiamente tal. Bajo este mismo campo de reflexiones, Campra también refiere a la exigencia intelectual de los estudios literarios para abordar por fuerza las proyecciones de lo fantasmal más allá de las restricciones de lo fantástico en tanto 
género literario pues, a su juicio, todo relato fantástico también cuenta con "su [propio] carácter polisémico, su valencia metafórica, su irradiación simbólica” (p. 80). Motivo por el que, la autora afirma que lo fantástico (y lo fantasmal incluido) amplifica el mundo de los significados posibles y de las implicaciones ideológicas, ampliando también sus motivos de origen y de originalidad.

El tercer capítulo, "Leer ficciones. Condiciones y consecuencias" remite a las posibilidades creativas de la lectura crítica; o bien, del quehacer crítico-creativo del lector de obras de ficción literaria. De este modo, bajo el entendido de la "libertad" del lector por parte de la crítica, Campra aboga por la constante fluctuación y necesaria inestabilidad de los sistemas literarios para la generación de nuevas lecturas posibles pues afirma que toda lectura, a la par de toda reflexión hacia la lectura es siempre una lectura situada y por lo mismo, "tributaria de su inscripción en un territorio epistemológico acotado por su circunstancia" (p. 111). En este capítulo, la autora también revisa con detallada erudición los fundamentos epistemológicos de los distintos enfoques teóricos o de las escuelas de pensamiento relacionadas con los estudios literarios acerca de lo fantástico y sus posibilidades de lectura, tales como estructuralismo, new criticism, estudios culturales y la crítica de la lectura, para luego dimensionar la necesaria libertad de percepción o de actitud de escucha del lector contemporáneo ante la recepción y proposición de sentidos en una obra literaria cualquiera, y también por el entendimiento de la literatura en tanto sitio de exploración. Porque, de cierta manera, cada lector/a elije tanto su forma de ser lector/a como también su forma de hacer lectura.

El cuarto capítulo, "El relato de sueños: ¿qué clase de tejido es un texto?" revisa diversas representaciones de lo onírico en tanto eje estructurante de los relatos fantásticos con fin de desplazar la idea de "trama" y "urdimbre" como imagen tradicional de la construcción narrativa de los sueños para proponer la noción de "red" o "malla", en tanto nueva forma de acercamiento a la estructura de los textos de ficción. Conforme con esto, Campra reflexiona respecto de los modos de representación que tienen los sueños en las ficciones de la vigilia y también por las perspectivas de análisis para los relatos que presentan a los sueños como un sustento de lo fantástico. Por último, Campra formula una particular teoría de la representación y estructura de los sueños en los textos fantásticos tomando como base las figuraciones también textiles relativas a la metáfora del "encaje", y ejemplificando sus contribuciones con un estudio pertinente "al encaje discursivo de los sueños" (p. 169) en la novela El sueño de los héroes de Adolfo Bioy Casares.

El quinto y último capítulo, "El envés de lo leído: desde el lugar de la escritura" funciona como una conclusión general del libro, referida a las diversas manifestaciones de lo insólito, caracterizándolo como un ejercicio de la escritura literaria que es a la vez crítico y creativo. Con ello, Rosalba Campra también reflexiona desde los matices de su propia experiencia de escritura en tanto mujer escritora; o bien, en su doble experiencia con lo fantástico de acuerdo con su posición de intelectual teórica, académica y crítica literaria, y en conformidad con su quehacer de creadora de mundos de ficción. 
Si Territorios de la ficción es sobre todo un libro teórico centrado en el estudio de las garantías del acontecimiento fantástico, tipos de narradores pertinentes, confiabilidad de la voz y sobre todo en lo que respecta a las isotopías de lo fantástico; En los dobleces de la realidad, es un libro que, si bien nos presenta nuevas y agudas reflexiones acerca de lo fantástico, también evidencia que estas reflexiones surgen del quehacer fabulador de una escritora de ficciones. De tal forma que las inquietudes críticas y teóricas presentadas por Campra, guardan origen en su propia escritura narrativa. Así entonces, En los dobleces de la realidad es también en los dobleces de la escritura, en tanto realidad vívida de Rosalba Campra, como quien habita entre la lúcida reflexión teórica y el sensible pensamiento de la creación.

Por ello, finalmente, En los dobleces de la realidad no solo contribuirá al amplio campo de reflexión de los estudios literarios relacionados con lo fantástico y su constante expansión e influencia tanto en la narrativa no mimética como también en otros géneros y modalidades no propiamente narrativas como el cómic, el teatro o la poesía, e incluso en otras formas artísticas como el cine, la plástica, los videojuegos y la música, sino también, sobre todo, en el interés, estudio y entendimiento de la propia obra literaria (teórica, narrativa y poética) de Rosalba Campra.

Ricardo Espinaza Solar Universidad Arturo Prat (Chile) respinaz@unap.cl 